\title{
Manajemen Asuhan Kebidanan Intranatal pada Ny "R" Gestasi 38-40 Minggu dengan Anemia Persalinan di RSUD Syekh Yusuf Tanggal 05 Juli 2018
}

\author{
${ }^{1}$ Nurmawati, ${ }^{2}$ Sitti Saleha, ${ }^{3}$ Nadyah
}

\begin{abstract}
ABSTRAK
Pendahuluan Persalinan memiliki resiko bagi ibu maupun janin terutama jika persalinan dengan anemia. Resiko yang dapat terjadi pada ibu dengan anemia pada persalinan adalah pada kala I dan kala II berlangsung lama sehingga dapat melelahkan dan sering memerlukan tindakan dan operasi kebidanan, pada kala III (kala uri) dapat diikuti retensio plasenta, post partum hemoragik karena atonia uteri, sedangkan pada kala IV dapat terjadi perdarahan post partum sekunder dan atonia uteri. Karya Tulis Ilmiah adalah studi kasus yang bertujuan untuk melaksanakan asuhan Manajemen Asuhan Kebidanan Intranatal pada Ny "R" dengan Anemia pada Persalinan di RSUD Syekh Yusuf Tahun 2018 sesuai dengan 7 Langkah Varney dan SOAP. Berdasarkan manajemen asuhan pada kasus ini keadaan ibu dan bayi baik, serta tidak terjadi komplikasi pada masa persalinan maupun pasca persalinan.

Kesimpulan Kesimpulan dari kasus yaitu 7 langkah Varney dan SOAP yang digunakan untuk proses penyelesaian masalah kebidanan telah dilaksanakan pengkajian berupa pemantauan dan analisa data $\mathrm{Ny}$ "R" dengan anemia pada persalinan di RSUD Syekh Yusuf tahun 2018 proses persalinan kala I sampai IV berlangsung normal, tanpa komplikasi, bayi lahir spontan dengan jenis kelamin perempuan, plasenta lahir kesan lahir lengkap dan telah dilakukan pendokumentasian semua temuan dan tindakan yang telah dilaksanakan pada $\mathrm{Ny}$ " $\mathrm{R}$ " dengan hasil tidak ditemukan kesenjangan antara teori dan kasusringan disertai BBLR.
\end{abstract}

\section{ABSTRACT}

Introduction Childbirth has a risk for both mother and fetus, particularly when it is anemia. The risks that can take place at the mothers with anemia in childbirth are at the first and second stage occurring for so long that can be tiring and often requires the midwifery action and surgery, can be followed by placental retention and hemorrhagic postpartum due to uterine atone at the third stage, while at the fourth stage it can occur a secondary postpartum bleeding and uterine atone. The scientific writing is a case study aimed to carrying out the care of Intranatal Midwifery Care Management on Mrs. "R" with Anemia at the Delivery in RSUD Syekh Yusuf in 2018 in accordance with 7 Steps of Varney and SOAP. Based on the care management in the case, the condition of mother and baby is good, and no complication during the delivery and postpartum.

The conclusion of the case is that 7 steps of Varney and SOAP applied for the process of midwifery problem solving has been conducted in the forms of monitoring and data analysis of Mrs. " $R$ " with anemia at the delivery in RSUD Syekh Yusuf in 2018 of normal delivery process from stage I to IV, no complication, femele baby spontaneously born wit complete placenta, and all findings as well as actions performed on Mrs. " $R$ " have been applied with the results of no gap between the theory and case.
*UIN Alauddin Makassar

Kata kunci :

Persalinan;

Anemia ;

Langkah Varney

Keywords:

Childbirth;

Anemia;

Varney Steps 


\section{PENDAHULUAN}

Anemia adalah suatu keadaan hemoglobin $(\mathrm{Hb})$ dalam darah kurang dari normal, berdasarkan kelompok umur, jenis kelamin dan kehamilan (WHO, 2013). Dalam pendapat lain anemia adalah kondisi dimana berkurangnya sel darah merah (erotrosit) dalam sirkulasi darah atau masa hemoglobin sehingga tidak mampu memenuhi fungsinya sebagai pembawa oksigen ke seluruh jaringan (Retnorini, dkk, 2017), sedangkan definisi anemia yang diterima secara umum adalah kadar $\mathrm{Hb}<12,0$ gram per $100 \mathrm{ml}(12 \mathrm{~g} / \mathrm{dL})$ untuk wanita tidak hamil dan $<10,0$ gram per $100 \mathrm{ml}(10 \mathrm{~g} / \mathrm{dL})$ untuk wanita hamil (Herlina, 2013).

Penyebab anemia dalam kehamilan adalah karena defisiensi zat besi (Fe) yang dapat disebabkan oleh kekurangan bermacam nutrien penting dalam pembentukan hemoglobin. Defisiensi Fe yang umum terjadi di dunia merupakan penyebab utama terjadinya anemia gizi. Anemia defisiensi besi merupakan salah satu gangguan yang paling sering terjadi terutama selama kehamilan (Retnorini, 2017).

Kekurangan zat besi sejak sebelum kehamilan bila tidak diatasi dapat mengakibatkan ibu hamil menderita anemia. Kondisi ini dapat meningkatkan resiko kematian pada saat melahirkan, melahirkan bayi dengan berat badan lahir rendah, janin dan ibu mudah terkena infeksi, keguguran dan meningkatkan resiko bayi lahir prematur (Kemenkes RI, 2015), dan komplikasi lain yang dapat ditimbulkan dari anemia dalam persalinan yang meliputi atonia uteri, retensio plasenta, partus lama dan perdarahan post partum merupakan bentuk dari tidak baiknya kontraksi rahim. Atonia uteri adalah kegagalan mekanisme kontraksi dan retraksi serat-serat miometrium, keadaan ini penyebab utama perdarahan post partum (Rudiyanti dan Diana, 2014).

Kekurangan kadar hemoglobin dalam darah mengakibatkan kurangnya oksigen yang dibawah ke sel tubuh maupun sel otak dan uterus. Jumlah oksigen dalam darah yang kurang menyebabkan disfungsi sel untuk meregenerasi. Pengaruh anemia saat persalinan dapat berupa gangguan his, partus lama dan perdarahan karena atonia uteri. Selain itu bahaya anemia selama persalinan kurangnya kekuatan saat mengejan, kala I dapat berlangsung lama sehingga dapat terjadi partus terlantar, kala II berlangsung lama sehingga dapat melelahkan, saat kala uri dapat diikuti retensio plasenta dan perdarahan post partum karena atonia uteri, 
kala IV terjadi perdarahan post partum sekunder dan atonia uteri (Rudiyanti dan Diana, 2014).

Anemia dialami oleh $85 \%$ wanita yang melahirkan pervaginam. Anemia perlu mendapatkan perhatian karena dapat menyebabkan disfungsi organ reproduksi wanita, sebagai sumber perdarahan, dan sumber atau jalan keluar masuknya infeksi, yang kemudian dapat menyebabkan kematian karena perdarahan atau sepsis (Manuaba dalam Rudi dkk, 2014). Dengan adanya komplikasi tersebut akan mengakibatkan mortalitas (kematian) dan morbilitas (kesakitan) ibu yang dapat menjadi faktor-faktor peningkatan Angka Kematian Ibu $(\mathrm{AKI})$.

Angka kematian Ibu (AKI) merupakan salah satu indikator penting dalam menentukan derajat kesehatan masyarakat. AKI menggambarkan kualitas pelayanan untuk ibu hamil, bersalin, dan nifas. Diseluruh dunia diperkirakan 216 kematian ibu per 100.000 kelahiran hidup (KH), tercatat 93 negara yang dilaporkan mengalami kemajuan signifikan. Namun badan kesehatan dunia juga mengungkapkan total hanya 9 negara saja yang benar- benar mencapai target perserikatan bangsa-bangsa (PBB), yaitu sedikitnya 75\% yaitu Bhutan, Cabo, Verde, Kamboja, Iran, Laos, Mangolia, Rwanda, dan Timor Leste (WHO, 2015).

Angka Kematian Ibu (AKI) di negara-negara Asia Tenggara yaitu Indonesia 214 per 100.000 kelahiran hidup, Filiphina 170 per 100.000 kelahiran hidup, Vietnam 160 per 100.000 kelahiran hidup, Thailand 44 per 100.000 kelahiran hidup, Brunei 60 per 100.000 kelahiraan hidup dan Malaysia 30 per 100.000 kelahiran hidup dan Indonesia menempati urutan tertinggi di Asia Tenggara (WHO, 2014).

Berdasarkan data Survei Penduduk Antar Sensus (SUPAS) di Indonesia AKI mengalami penurunan dari 359/100.000 kelahiran hidup (KH) pada tahun 2012 menjadi $305 / 100.000 \mathrm{KH}$ pada tahun 2015. Penyebab kematian ibu yakni perdarahan $(35,2 \%)$, hipertensi $(27,1 \%)$, infeksi $(7,3 \%)$, partus lama (1,8\%), dan abortus (4,7\%) (Profil Kesehatan Indonesia, 2016).

Berdasarkan Profil Kesehatan Sulawesi Selatan, AKI mengalami peningkatan dari tahun 2014 yaitu 138/100.000 KH atau (93,20\%) meningkat menjadi 149/100.000 KH atau $(99,38 \%)$ pada tahun 2015. Penyebab AKI terdiri dari perdarahan $(41,61 \%)$, hipertensi dalam 
kehamilan (21,48\%), infeksi (4,03\%), gangguan sistem peredaran darah $(8,72 \%)$, gangguan metabolik (2,01\%), dan penyebab lain (22,15\%) (Profil Kesehatan Sulsel, 2015 dan 2017).

Kejadian anemia di Indonesia relatif tinggi yaitu $63,5 \%$, yang setiap daerah mempunyai variasi berbeda, anemia merupakan salah satu penyebab persalinan lama sebagaimana hasil penelitian yang dikemukakan oleh Ratna Arista Dwi Andriani tahun 2016 menunjukkan terdapat hubungan anemia pada kehamilan dengan inpartu kala II lama (Andriani, 2016).

Berdasarkan data rekam medik Rumah Sakit Umum Daerah Syekh Yusuf Kabupaten Gowa menunjukkan jumlah persalinan pada periode 2015 yaitu 1.804 yang diantaranya terdapat $23(1,27 \%)$ kasus persalinan dengan anemia pada persalinan, pada tahun 2016 yaitu 1.578 persalinan yang diantaranya $19(1,20 \%)$ dengan anemia pada persalinan, dan pada tahun 2017 tercatat 2.642 persalinan yang diantaranya $13(0,49 \%)$ kasus dengan anemia pada persalinan (Rekam Medik RSUD Syekh Yusuf Kabupaten Gowa, 2017).

Mengingat bahaya yang ditimbulkan oleh kejadian anemia pada persalinan maka perlu penanganan secara kolaborasi dari petugas kesehatan dalam pencegahan komplikasi untuk menurunkan Angka Kematian Ibu (AKI) di Indonesia maka penulis tertarik untuk menerapkan asuhan kebidanan dengan tujuan pencegahan komplikasi yang ditimbulkan dari anemia dalam persalinan.

\section{METODE PENELITIAN}

Jenis penelitian ini adalah studi kasus dengan pendekatan Manajemen Kebidanan sesuai dengan 7 Langkah Varney dan pendokumentasin dalam bentuk SOAP. Penatalaksanaan Asuhan dilakukan dengan pemberian asuhan yang sesuai standar operasional prosedur pada kasus yang diteliti yaitu anemia pada persalinan serta melakukan upaya pencegahan komplikasi yaitu : pada kala I dan kala II berlangsung lama sehingga dapat melelahkan dan sering memerlukan tindakan dan operasi kebidanan, pada kala III (kala uri) dapat diikuti retensio plasenta, post partum hemoragik karena atonia uteri, sedangkan pada kala IV dapat terjadi perdarahan post partum sekunder dan atonia uteri. Serta dilakukannya pemantauan dan asuhan dari kala I sampai kala IV. 


\section{HASIL PENELITIAN}

Penelitian ini dilakukan di RSUD Syekh Yusuf Kabupaten Gowa tepat dengan pembahasan tentang asuhan kebidanan intranatal pada Ny"R" dengan Anemia pada Persalinan tanggal 5 Juli 2018. Pembahasan ini dibuat berdasarkan landasan teoritis dan studi kasus yang dapat dianalisa secara teoritis untuk memudahkan memahami kesenjangan dan kesesuaian yang terjadi pada kasus ini dengan berdasarkan pada pendekatan asuhan kebidanan dengan tujuh langkah varney yakni : pengumpulan data dasar, merumuskan diagnosis atau masalah potensial, melaksanakan tindakan segera atau kolaborasi, merencanakan tindakan asuhan kebidanan.

\section{Kala I}

Berdasarkan hasil pengkajian pada kasus Ny"R" didapatkan data subjektif dan objektif menunjukkan bahwa diagnosis inpartu kala I fase aktif dengan Anemia. Hasil yang diperoleh pada kasus Ny "R" yaitu pada kala I berlangsung \pm 10 jam, keadaan ibu lemah dan janin baik, dan tidak ada komplikasi yang terjadi pada ibu dan bayi. Dengan demikian seorang bidan harus tetap memberikan dukungan psikologis dan spiritual kepada ibu dan keluarga sangat penting agar tetap tenang dalam menghadapi persalinannya yaitu dengan memperbanyak berdoa, berdzikir, istighfar, membaca dan mendengarkan lantunan ayat suci Al- Quran

\section{Kala II}

Berdasarkan pengkajian pada kala II pada kasus Ny "R" didapatkan data subjektif ibu merasakan adanya dorongan kuat untuk meneran. Sedangkan data objektif didapatkan tampak perineum menonjol, vulva dan vagina membuka, pada pemeriksaan dalam didapatkan pembukaan serviks telah lengkap. Pada kasus Ny "R" kala II berlangsung normal yaitu bayi lahir spontan pada tanggal 5 Juli 2018 jam 12.25 WITA, segera menangis, dan bergerak aktif dengan berat badan lahir 2700 gram, panjang badan $47 \mathrm{~cm}$. Tinggi fundus uteri setinggi pusat. Berdasarkan pengkajian yang telah dilakukan pada Ny "R" di kala II tidak ditemukan kesenjangan antara teori dan kasus. 


\section{Kala III}

Pada kasus Ny"R" didapatkan hasil pemeriksaan dalam keadaan normal ditandai dengan uterus teraba keras dan bundar, tinggi fundus uteri setinggi pusat yang berarti kala III berlangsung normal, serta tidak ada kesenjangan antara teori dan praktek yang dilakukan.

\section{Kala IV}

Pada kasus Ny"R" didapatkan kontraksi uterus baik teraba keras dan bundar, tinggi fundus uteri 1 jari bawah pusat, kandung kemih kosong, jumlah perdarahan $\pm 150 \mathrm{cc}$. Hasil evaluasi ini membuktikan bahwa kala IV berlangsung normal dan tidak ada penyulit serta tidak ada kesenjangan antara teori dan praktek.

\section{PEMBAHASAN}

\section{Kala I}

Berdasarkan data subjektif dan data objektif pada kasus Ny "R" didapatkan diagnosis inpartu kala I fase aktif dengan anemia sedang Sesuai dengan teori penetapan fase aktif berdasarkan pembukaan serviks, dimana fase laten dimulai sejak awal kontraksi yang menyebabkan penipisan dan pembukaan serviks secara bertahap kurang dari $4 \mathrm{~cm}$ dan fase aktif dimulai sejak pembukaan serviks $4-10 \mathrm{~cm}$ dan pada umumnya frekuensi dan lama kontraksi uterus meningkat (Oktarina, 2016: 13).

Anemia adalah suatu kondisi yang terjadi ketika jumlah sel darah merah (eritrosit) dan/atau jumlah hemoglobin yang ditemukan dalam sel darah merah menurun dibawah normal. Hal ini dapat menyebabkan masalah kesehatan karena sel darah merah mengandung hemoglobin yang membawa oksigen ke jaringan tubuh. Tanpa kecukupan pasokan oksigen, banyak jaringan dan organ dalam tubuh dapat terganggu. Anemia dapat menyebabkan berbagai komplikasi termasuk kelelahan dan stress pada organ tubuh (Proverawati dalam Marmi, 2014).

Komplikasi lain yang dapat ditimbulkan dari anemia dalam persalinan yang meliputi atonia uteri, retensio plasenta, partus lama dan perdarahan post partum merupakan bentuk dari tidak baiknya kontraksi rahim. Atonia uteri adalah kegagalan mekanisme kontraksi dan 
retraksi serat-serat miometrium, keadaan ini penyebab utama perdarahan post partum (Rudiyanti dan Diana, 2014).

Diagnosis anemia pada persalinan ditegakkan dengan pemeriksaan fisik dengan keadaan ibu lemah, konjungtiva pucat dan dilakukan pemeriksaan laboratorium hemoglobin $8,9 \mathrm{gr} / \mathrm{dL}$ normalnya pada wanita hamil kadar hemoglobin dalam darah yaitu $\geq 11 \mathrm{gr} / \mathrm{dl}$ selama kehamilan pada trimester 1 dan ke 3 , dan $\geq 10 \mathrm{gr} / \mathrm{dl}$ selama post partum dan trimester 2 (Retroniri, 2017).

Bidan harus mampu mengenali tanda dan gejala dari anemia pada persalinan agar dapat melakukan asuhan kebidanan yang sesuai, kolaborasi dan komprehensif terhadap ibu. Dalam melakukan asuhan hendaklah selalu berdoa kepada Allah agar asuhan yang diberikan dapat meringankan keluhan ibu sehingga ibu dapat merasa lebih baik. Teori mengatakan masalah potensial yang dapat terjadi pada kasus anemia dalam persalinan yaitu partus terlantar karena dengan kurangnya kadar hemoglobin dalam darah mengakibatkan kurangnya oksigen yang dibawah ke sel tubuh maupun sel otak dan uterus. Jumlah oksigen dalam darah yang kurang menyebabkan disfungsi sel untuk meregenerasi dan mengakibatkan otot untuk berelaksasi dan selama persalinan akan mengakibatkan kontraksi uterus melemah dan kurangnya kekuatan ibu saat mengejan sehingga dapat melelahkan (Tando, 2013: 26).

Berdasarkan data dalam penerapan asuhan kebidanan pada Ny "R" didapatkan data yang menunjukkan terjadinya partus terlantar dengan kontraksi uterus yang melemah dan keadaan ibu lemah. Sambil mengamati klien, bidan diharapkan bersiap-siap apabila terjadi masalah potensial. Selain itu bidan dapat memberikan pemahaman kepada ibu bahwa kehamilan dan persalinan adalah anugrah dari Allah swt. dengan diberikan kepercayaan tersebut ibu mampu menghadapi dan bersabar dengan keluhan yang dirasakannya.

Tindakan ini dilakukan jika ditemukan adanya diagnosa potensial atau masalah emergency sehingga membutuhkan tindakan segera atau tindakan kolaborasi. Berdasarkan penerapan asuhan kebidanan terhadap $\mathrm{Ny}$ " $\mathrm{R}$ " didapatkan data yang menunjang yaitu pemeriksaan fisik dan laboratorium untuk dilakukan tindakaan kolaborasi dengan dokter Obgyn untuk mengantisipasi komplikasi-komplikasi terhadap ibu dan janin, menganjurkan ibu untuk beristigfar dan berdoa kepada Allah swt. serta tidak menjadikan keluhannya saat ini menjadi beban sehingga tidak semakin memperburuk kondisi ibu. 
Rencana tindakan dibuat berdasarkan intervensi yang dibuat sebelumnya. Rencana tindakan dibuat sesuai dengan teori yaitu memasangkan infuse yang di drips $1 / 2$ ampuls okstosin dalam $500 \mathrm{ml} \mathrm{RL}$, memantau tekanan darah dan suhu setiap 4 jam, memantau DJJ, nadi, dan his setiap 30 menit serta memantau kemajuan persalinan setiap 2-4 jam.

Berdasarkan penerapan asuhan kebidanan terhadap Ny "R" didapatkan telah diberikan pendekatan terapeutik kepada ibu dan keluarga dengan memberikan motivasi dan dukungan emosional dengan lebih mendekatkan diri kepada Allah swt. dengan memperbanyak dzikir, istigfar, membaca dan mendengarkan lantunan ayat suci Al- Qur'an agar ibu lebih tenang dan tidak terlalu memfokuskan fikirannya dengan kondisinya saat ini.

\section{Kala II}

Berdasarkan penerapan asuhan kebidanan pada Ny "R" didapatkan data subjektif ibu merasakan adanya dorongan yang kuat untuk meneran dan ibu merasa ingin BAB. Sedangkan data objektif yang didapatkan perineum menonjol, vulva, vagina dan anus membuka. Djj dalam batas normal, his 5 kali dalam 10 menit durasi 45-50 detik, pemeriksaan dalam pada pukul 12:00 WITA didapatkan pembukaan $10 \mathrm{~cm}$, ketuban jernih, presentasi uuk depan, penurunan hodge IV, molage 0 , pelepasan air ketuban dan darah.

Teori mengatakan tanda gejala kala II, yaitu ibu merasakan ingin meneran bersamaan dengan terjadinya kontraksi, ibu merasakan adanya peningkatan tekanan pada rectum dan atau vaginanya, perineum menonjol, vulva, vagina dan sfingter ani membuka, meningkatnya pengeluaran lendir bercampur darah (Nurasiah dkk, 2014).

Pada langkah selanjutnya, berdasarkan intervensi yang dilakukan meliputi melihat ada tanda dan gejala kala II, siapkan alat dan bahan persalinan, pastikan pembukaan lengkap, periksa keadaaan janin, siapkan ibu dan keluarga untuk membantu proses persalinan, dan menganjurkan untuk membaca basmalah saat mulai mengedan, letakkan handuk bersih di atas perut ibu dan underpad di bawah bokong ibu, pimpin persalinan jika kepala sudah membuka vulva 5-6 cm, periksa lilitan tali pusat, tunggu kepala bayi melakukan putaran paksi luar secara spontan, kemudian melanjutkan melahirkan bahu depan dan bahu belakang, setelah kedua bahu bayi lahir dilanjutkan dengan sanggah susur untuk melahirkan badan bayi, setelah bayi lahir jepit dan potong tali pusat kemudian bersihkan badan bayi lalu lakukan penilaian sepintas, dan segerakan untuk IMD. 
Pada kasus Ny"N" didapatkan bayi lahir spontan dengan presentasi belakang kepala tanggal 5 Juli 2018 jam 12.25 WITA dengan jenis kelamin perempuan dengan BB : 2700 gram, PB : $47 \mathrm{~cm}$. Setelah bayi lahir cek fundus uteri untuk memastikan kehamilan tunggal, kemudian memberitahu ibu untuk penyuntikan oksitosin, suntik oksitosin. Setelah ibu melewati proses persalinan, ibu diingatkan untuk bersyukur atas nikmat keselamatan yang diberikan dan senantiasa menerima dengan lapang dada apapun yang terjadi karena segala sesuatu itu semuanya terjadi atas rencana Allah swt kepada umat-Nya.

Inisiasi Menyusu Dini ini untuk menjalin kasih sayang antara ibu dan bayi, selain itu agar bayi tetap mempertahankan suhu tubuh dan menciptakan ikatan batin sambil bayi berada dipelukan ibunya, ibu dianjurkan untuk membisikan kalimat-kalimat tauhid kepada bayinya agar kelak menjadi anak yang solehah.

\section{Kala III}

Pada kasus Ny"N" didapatkan hasil pemeriksaan dalam keadaan normal ditandai dengan uterus teraba keras dan bundar, tinggi fundus uteri setinggi pusat yang berarti kala III berlangsung normal, serta tidak ada kesenjangan antara teori dan praktek yang dilakukan.

Berdasarkan teori yang didapatkan asuhan persalinan kala III dimulai segera setelah bayi sampai lahirnya plsenta yang berlangsung tidak lebih dari 30 menit. Setelah bayi lahir uterus teraba keras dengan fundus uteri agak di atas pusat untuk melepaskan plasenta dari dindingnya. Tanda-tanda terlepasnya plasenta yaitu perubahan bentuk dan tinggi fundus uteri, tali pusat memanjang, tali pusat terlihat menjulur keluar melalui vulva, semburan darah tibatiba (Walyani, 2015).

Pada kasus Ny "N" dilakukan intervensi yang sesuai yaitu pemberian oksitosin, peregangan tali pusat dan masase uterus. Periksa tinggi fundus uteri untuk memastikan tidak ada janin, pemberian oksitosin dilakukan setelah 1 menit bayi lahir. Setelah itu, suntikkan oksitosin secara IM di sepertiga bagian atas paha ibu dan segera lakukan IMD. Pada kasus Ny"N" melakukan pemberian oksitosin secara IM, kemudian melakukan peregangan tali pusat terkendali untuk melahirkan plasenta, lakukan masase uterus setelah plasenta lahir. Proses pelepasan dan pengeluaran plasenta berlangsung normal tanpa penyulit. Plasenta lahir 5 menit setelah bayi lahir yaitu jam 12.30 WITA, plasenta lahir lengkap dengan kotiledon dan 
selaput ketuban utuh, perdarahan $\pm 200 \mathrm{cc}$ dan segera dilakukan IMD untuk mencegah terjadinya hipotermi.

\section{Kala IV}

Pada kasus Ny"N" didapatkan kontraksi uterus baik teraba keras dan bundar, tinggi fundus uteri 1 jari bawah pusat, kandung kemih kosong, jumlah perdarahan $\pm 150 \mathrm{cc}$. Hasil evaluasi ini membuktikan bahwa kala IV berlangsung normal dan tidak ada penyulit serta tidak ada kesenjangan antara teori dan praktek.

Berdasarkan teori pada kala IV hal-hal yang harus diperhatikan yaitu kontraksi uterus baik, pemeriksaan serviks, vagina dan perineum untuk mengetahui terjadinya laserasi jalan lahir yang dapat diketahui adanya perdarahan setelah persalinan. Tanda- tanda vital ibu dan keadaan bayi (Kuswanti, 2014).

Teori mengatakan salah satu penyebab kematian ibu pada waku nifas adalah perdarahan postpartum.Kematian ibu disebabkan oleh infeksi, perdarahan dan atonia uteri. Maka dengan demikian, pemantauan sangat penting selama 2 jam postpartum (Saleha, 2013).

\section{KESIMPULAN DAN SARAN}

\section{A. KESIMPULAN}

1. Telah dilakukan pengkajian dan analisis data dasar pada Ny " $R$ " dengan anemia pada persalinan di RSUD Syekh Yusuf tahun 2018. Pada kasus Ny. "R" didapatkan data dasar dengan Hemoglobin 8,9 gr/dL.

2. Telah dilakukan pengidentifikasian diagnosa/ masalah aktual pada Ny "R" dengan anemia pada persalinan di RSUD Syekh Yusuf Gowa Ny. "R" masuk dengan tanda dan gelaja inpartu dan keluhan lain yang menyertai pusing pada kepala dan merasa lemas.

3. Telah dilakukan pengidentifikasian diagnosa/ masalah potensial pada $\mathrm{Ny}$ " $\mathrm{R}$ " dengan anemia pada persalinan di RSUD Syekh Yusuf Gowa diantisipasi terjadinya partus terlantar dan asfiksia neonatorum, atonia uteri, retensio plasenta, partus lama dan perdarahan post partum.

4. Telah dilakukan tindakan segera dan kolaborasi pada Ny "R" dengan anemia pada persalinan di RSUD Syekh Yususf. Kolaborasi dilakukan bersama dokter obgyne untuk tindakan pencegahan 
5. Telah dilakukan penyusuanan rencana tindakan asuhan kebidanan pada Ny " $R$ " dengan anemia pada persalian di RSUD Syekh Yususf Gowa tahun 2018. Intervensi dilakukan dengan pemantaauan persalinan dengan partograf, pemberian infuse RL drips oksitosin $1 / 2$ ampuls dalam $500 \mathrm{ml}$, perencanaan persalinan dengan hati- hati.

6. telah dilakukan tindakan asuhan kebidanan pada $\mathrm{Ny}$ " $\mathrm{R}$ " dengan anemia pada persalian di RSUD Syekh Yususf Gowa tahun 2018. Telah dilakukan sesuai dengan intervensi, bayi lahir pada pukul 12.25 wita berjenis kelamin perempuan, berat badan lahir 2700 gram, panjang badan $47 \mathrm{~cm}$ dan apgar skor 8/10.

7. telah dilakukan evaluasi asuhan kebidanan pada nyonya $\mathrm{R}$ dengan anemia pada persaalinan di RSUD Syekh Yususf tahun 2018. Konsisi ibu baik dan tidak terjadi perdarahan post partum

\section{B. SARAN}

Berdasarkan tingakat resiko yang dapat disebabakan oleh anemia pada persalinan maka penulis menyarankan :

1. Meningkatkan upaya pencegahan terjadinya anemia pada persalinan dengan pelayanan antenatal care yang sesuai standar

2. Mengenali sedini mungkin komplikasi-komplikasi pada kehamilan dan upaya penanganan.

3. Melakukan pertolongan anemia pada persalinan dengan baik yaitu salah satunya dengan menjalin hubungan saling percaya yang baik dengan pasien, keluarga pasien dan tenaga kesehatan lain

\section{DAFTAR PUSTAKA}

Andriani, Dwi : Hubungan Anemia pada Kehamilan dengan Inpartu Kala II Lama, Jurnal Ilmiah Kesehatan, Surabaya Vol. 9 No. 1, Februari 2016.

Aundrey, dkk: Hubungan Antara Status Anemia Ibu Hamil Trimester III dengan Kejadian Bayi Berat Lahir Rendah di Wilayah Kerja Puskesmas Halmahera, Jurnal Kedokteran Diponegoro, Semaranng Vol. 5. No. 4, Oktober 2016.

Damayanti, Ika, dkk, Buku Ajar Asuhan Kebidanan Komprehensif Pada Ibu Bersalin Dan Bayi Baru Lahir, Yogyakarta: Deepublish, 2014.

Dinas Kesehatan Provinsi Sulawesi Selatan, Profil Kesehatan Sulawesi Selatan, 2015 dan 2017

Firdayanti, Arifuddin Ahmad, Buku Dasar Persalinan (Askeb II), Alauddin University Press, 2007. 
Herlina: Hubungan Anemia dan Partus Lama dengan Kejadian Perdarahan Postpartum di RSUD Pringsewu, Jurnal Kesehatan Metro Sai Wawai, Vol. VII, No. 1, Edisi Juni 2014.

Indrayani, dkk, Asuhan Persalinan Dan Bayi Baru Lahir, Jakarta: CV. Trans Info Media, 2013

Kementrian Agama RI, Al-Qur'an Terjemah dan Tajwid, Bandung: PT Sigma Examedia Arkanleema, 2015.

Kementrian Kesehatan RI, Profil Kesehatan Indonesia, 2016

Kuswanti, Ina. Melina Fitriani, Askeb II Persalinan, Yogyakarta: Pustaka Pelajar, 2016.

Lailiyaana, dkk, Asuhan Persalinan Neonatal dan Bayi Baru Lahir, Jakarta: Pustaka Medika, 2012.

Marmi, dkk, Asuhan Kebidanan Patologi, Yogyakarta: Pustaka Pelajar, Cetakan Kedua. 2014.

Nadyah, Kegawatdaruratan Neonatal, Anak dan Maternal, Alauddin University Press, 2013.

Nirwan dan Zulkarnain: Aterm Pregnancy Inpartu Singular Embrio Life Presentation Of Head With Partus Kasep, Vol. 2. No. 3. 2014.

Prawirohardjo, Sarwono, 2014. Ilmu Kebidana,. Jakarta: Pt. Bina Putaka Sarwono

Purwaningsih dan Sitti Fatimah, Asuhan Keperawatan Maternitas, Yogyakarta: Nuha Medika. 2010,

Oktarina, Mika, Buku Ajar Asuhan Kebidanan Persalinan Dan Bayi Baru Lahir, Yogyakarta: Deepublish, 2016.

Rahmawati, dkk: Hubungan Partus Lama dan Anemia Dengan Kejadian Perdarahan Postpartum di Ruang VK Bersalin RSUD Dr. H. Moch Ansari Saleh Banjarmasin, Jurnal Dinamika Kesehatan, Vol. 7, No. 2, Desember 2016.

Rekam Medik RSUD Syekh Yusuf Kabupaten Gowa, 2017

Retnorini, dkk: Pengaruh Pemberian Tablet Fe dan Sari Kacang Hijau Terhadap Kadar pada Ibu Hamil, Jurnal Kebidanan, Vol. 6, No. 12, April 2017.

Rudiyanti, dkk: Anemia Dan Kontraaksi Rahim Dalam Proses Persalinan, Jurnal Keperawatan, Vol. X, No. 1, April 2014.

Rudy dan Lia: Gambaran Kejadian Anemia padaIbu Hamil di RB Nasyithoh Kecamatan Tambun Kabupaten Bekasi, Jurnal Kesehatan Bhakti Husada. Tahun 2014.

Saleha, Sitti, Asuhan Kebidanan II Persalinan, Alauddin University Press, 2012.

Saleha, Sitti, Asuhan Kebidanan pada Masa Nifas, Jakarta: Salemba Madika, 2013.

Shihab M. Quraish. Tafsir Al-Mishbah pesan, kesan dan keserasian Al- Qur'an, Vol. 12, Jakarta: Lentera hati, 2009.

Tando, Naumi, Asuhan Kebidanan Persalinan Dan Bayi Baru Lahir, Jakarta: Penerbit In Media, 2013.

Walyani, Proastuti., Asuhan Kbidanan Persalinan dan Bayi Baru Lahir, Yogyakarta: Pustaka Medika, 2015.

Yanti, Buku Ajar Asuhan Kebidanan Persalinan, Yogyakarta: Pustaka Rihama. 2014. 